\title{
Dekiler-Box Sterility Test as an Innovation in Multifunction Sterilization Equipment for Dental Instruments
}

\author{
Wimmy Safaati Utsani ${ }^{1}$, Tifani Nazarudin ${ }^{2}$, Ardhita Rosiana Putri ${ }^{1}$, \\ Muhammad Abu Chaira ${ }^{1}$, Bachuroh Fasda ${ }^{1}$, Dendy Murdiyanto ${ }^{3^{*}}$ \\ ${ }^{1}$ Faculty of Dentistry, Muhammadiyah University of Surakarta, Indonesia \\ ${ }^{2}$ Faculty of Engineering, Muhammadiyah University of Surakarta, Indonesia \\ ${ }^{3}$ Department of Dental Material, Faculty of Dentistry, Muhammadiyah University of Surakarta, \\ Indonesia \\ *Email: dendymurdiyanto@ums.ac.id
}

\begin{abstract}
Sterilization is the process of destroying or eliminating all microorganisms. The aim of sterilization is to destroy every form of pathogenic microorganism including spores that might adhere to dental instruments and associated equipment. Dental instruments that come in direct contact with the human body have a very high risk of transmitting diseases caused by microorganisms; therefore, it is important to keep the instruments sterilized. The Dekiler Box is an innovation in sterilization equipment to help dentists in rural areas. This piece of equipment has several advantages, including practicality, multifunctions, portability, and zero use of electricity. The aim of this study was to determine the sterilization effectiveness of the Dekiler Box through differences in the quantities of bacteria on dental instruments compared to an autoclave. This was an experimental study that compared dental instruments before use, after use, and after being sterilized with the Dekiler-Box sterilization equipment. The results showed that bacteria increased significantly after instrument use and decreased after sterilization with the Dekiler Box. In conclusion, sterilization of dental instruments using the Dekiler Box was effective for reducing bacteria on dental instruments.
\end{abstract}

Keywords: sterilization, dekiler-box, practical, multifunction, innovation

\section{Introduction}

Infection is an invasive process by microorganisms proliferating inside the human body that causes illness, and several diseases are caused by growth of pathogenic organisms inside the body [1]. Infection can occur for several reasons, such as pathogenic microorganisms, including bacteria, virus, and fungi. Microorganisms must reproduce and relocate to survive [2]. Many microorganisms are found in hospitals and clinics because these locations are centers for unhealthy people who might bring dangerous microorganisms into the building. Hospitals as medical service units are responsible for treating infectious patients with microorganisms.

Dentists and all health practitioners in the field of dentistry are expected to assume that all patients have the potential to bring in some infection [3]. A patient's oral cavity is the main cause of infection. Several bacteria, viruses, and fungi can be transmitted during dental treatment procedures. The safest way to prevent in- 
fections from spreading is to apply standard precautionary procedures to control infection. Infection control includes doing everything possible to prevent transmission of potential pathogenic microorganisms [3]. Dentists have the responsibility to always fulfill one of the standard criteria of dental service in Indonesia of preventing and controlling infections. Dentists must make sure that all services performed in their environment have proper infection prevention and control. This includes hand cleaning and proper cleaning, disinfection, and sterilization of instruments and materials before use. Dentists as health practitioners play a role in preventing and treating the oral cavity. While doing their tasks, dental health practitioners are prone to direct or indirect contact with microorganisms inside the patients' mouth (including saliva and blood). Continuous exposure to microorganisms causes a higher incidence of infectious diseases in dental practice. Neglecting effective infection control and prevention procedures can increase the risk of contracting infectious disease, including the family of the health practitioner and other patients [4]. Transmission of an infection can occur through direct or indirect contact with patients. Air contributes to cross infections [5].

Sterilization is the process of eliminating every form of microorganism including spores using physical or chemical procedures [6]. One of the objectives of sterilization in the health field is to prevent cross infections. In dentistry, this is important to prevent cross infection associated with sterilization of reusable instruments [7] Dental instruments are categorized as critical, semi-critical, or noncritical, depending on the potential infection risk associated with their intended use. Critical instruments used to penetrate soft tissues or bones have a higher risk of infection transmission. Semicritical instruments, which touch the mucous membranes or skin, have a relatively lower risk of infection transmission, and thus can be processed with high level disinfection. All dental instruments consist of a handle, shank, and active side. The active side is the part that interacts with soft tissues or mucous, such as the beak of a forceps or the blade of an elevator [7].

Equipment sterilization processes and storage are important in dental practice. Routine sterility testing is needed to examine whether there is any contamination of sterilized instruments, particularly reusable instruments. Instruments are considered sterile when the sterilization process kills all bacteria and spores [8]. Several studies have suggested that the autoclave is the most used sterilization method by health practitioners because it gives the best results at eliminating all microorganisms. A study conducted by Anggia at the University of Indonesia in 2012 concerning the effectiveness of several sterilization methods showed that the autoclave is the best sterilization method because it results in the minimum quantity of bacteria [9] The Dekiler-Box sterilization equipment uses a pressure cooker as a simpler alternative to an autoclave. Pressure cookers have a similar principle as that of an autoclave, except a pressure cooker does not require electricity [10].

Instrument sterilization or disinfection in dentistry is divided into several steps. There are five areas that need to be sterilized, including the cleaning area, instruments (dirty zone), sterilization area, clean instrument storage (clean zone), and the patient treatment area (work zone), which must be separated from each other. The dirty zone should be placed as far away as possible from the clean and working zones [10]. Pre-cleaning is performed by immersing instruments with deter- 
gent solution to release stains, blood, fat, and other body fluids from the instruments to facilitate the next procedure. This process takes 5-10 min depending on the product used $[4,10]$. All instruments used in treatment must be cleaned using soap and water with a brush or toothbrush to remove all organic materials (blood and saliva) and other dirt. After brushing, all instruments and equipment are rinsed in running water or water stored in a container (changed periodically) to remove soap residue. Then, the instruments are dried with clean towels $[4,10]$. Instruments directly touching bone or soft tissues or contaminated with blood must be sterilized. The instruments can be disinfected by boiling in a water-filled pressure cooker for $20 \mathrm{~min}$. The time is counted from the moment the water boils. After the water boils, no water or instruments are allowed to be added during the disinfection process $[4,10]$ Then, unwrapped instruments can be used immediately or stored in a sterilized or disinfected marked container indicating that the instruments inside that container have been sterilized. Instruments must be stored in a closed location (cabinet, drawer, or container) and must be reused in less than 1 week $[4,10]$

The various microorganisms inside the oral cavity can be divided into normal and transient flora. Normal flora is the group of microorganisms living on the skin and mucous membranes of healthy and ill people. The growth of normal flora on a certain part of the body is affected by temperature, moisture, nutrition, and inhibitors. The normal flora on certain parts of the body play an important role in the body's immune system because they produce substances that inhibit the growth of other microorganisms. Normal flora is not always advantageous, as it may cause disease under certain conditions if there is a change in the substance or relocation from its proper habitat [11].

Normal flora inside the oral cavity consists of Staphylococcus sp., Lactobacillus sp., and Streptococcus mutans/Streptococcus viridans. Despite their existence as normal flora, these bacteria may become pathogenic under certain conditions because of predisposing factors, such as poor oral hygiene.

Dentists not only practice in health clinics in cities or private clinics, but also may be obliged to do an internship in a rural area. The limitations of the facilities available in rural areas has become the main concern for treatment. The lack of proper facilities can cause poor service. The most important healthcare principle is patient protection from transmission of infection. An innovation of the equipment used to control and prevent infection has been made with the Dekiler-Box to realize proper healthcare and implement effective infection control and prevention. The expected objectives from the Dekiler-Box are:

a. To invent a concept for practical and portable sterilization of dental instruments.

b. To help dentists in rural areas prevent infection transmission before diagnosis and treatment.

c. To invent a dental instrument to sterilize equipment with several functions.

The purposes of the Dekiler-Box sterilization equipment are to:

a. Open the possibility of a new business in dentistry.

b. Increase students' innovative mind for inventing. 
c. Answer dentists' problems, particularly in rural areas, concerning sterilization procedures in poorly facilitated environments.

with this Dekiler-Box (Fig 1), we hoped that:

a. Dentists in rural areas with a lack of facilities can sterilize their dental instruments more easily.

b. This equipment will minimize instrument expenses.

c. This portable multifunction device can be used as prevention and protection from infection.

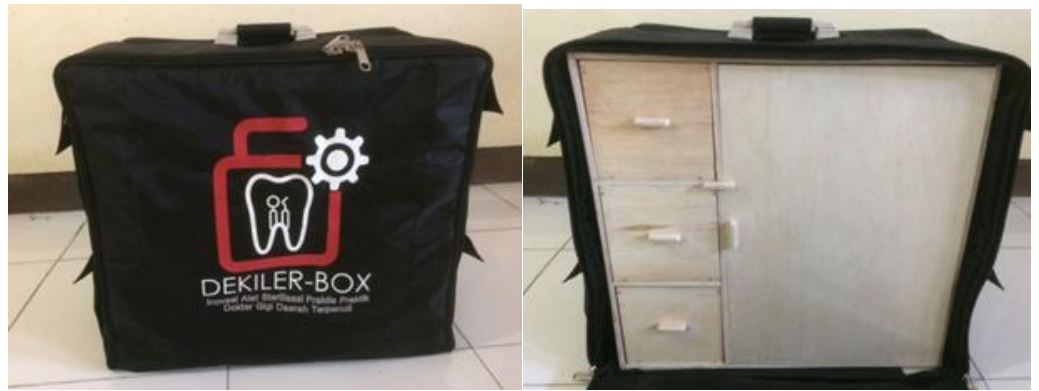

Fig. 1. Dekiler Box as an innovation in multifunction sterilization equipment for dental instruments

\section{Materials and Methods}

This was an experimental study involving treatment of subjects and followed strict controls of external factors [12]. Samples were sterilized using the Dekiler Box at the student's clinic of the Faculty of Dentistry, Muhammadiyah University, Surakarta and were examined at the Microbiology Laboratory of the Pharmacy Faculty of Muhammadiyah University, Surakarta. The treatments wre divided into three parts, before immersion in the disinfecting solution, after use inside the oral cavity but not sterilized, and after use inside the oral cavity and sterilized using the Dekiler Box [13]. The instruments used in this experiment were randomly picked dental instruments used for dental treatment at the student's clinic of the Dentistry Faculty of Muhammadiyah University, Surakarta.

The following tools and dental instruments were used: Dekiler Box, sterile towels, labels, reaction tube, alcohol lamp, beaker glass, analytical balance, hotplate, plastic wrap, aluminum foil, cotton, micropipettes, pit, oven, Petri dishes, incubator, marker, vortex, objective glass, and bacterial colony counter. The following materials were used: pepton, agar count plates, $\mathrm{NaCl}, 70 \%$ alcohol, disinfecting liquid, and distilled water.

\subsection{Sampling procedure}

A microorganism sample was taken from dental instruments submerged in pepton. Nine samples were put into labeled containers. Label A was given to the samples before the instrument was used for examination and treatment. Label B was given to instruments used for treatment. Label $\mathrm{C}$ was given to sample instruments sterilized with the Dekiler Box. The active side of instruments to be used during a den- 
tal examination and treatment were dipped in pepton for $15 \mathrm{sec}$ and labeled A to sample bacteria from the instrument. After the instrument was used, the active side was dipped in pepton labeled with letter B. The instrument was cleaned using a disinfectant and rinsed under flowing water. The dried instrument was then put in a sterilization bag, wrapped tightly, and sterilized in the Dekiler Box for $20 \mathrm{~min}$. The active side of the sterilized instrument was dipped in pepton and put into the $\mathrm{C}$ labeled container. All containers were closed tightly to avoid contamination.

\subsection{Platelet Count Agar Media}

The operator's hands and work table were sterilized with $70 \%$ alcohol and then dried. A 4.4 g portion of PCA (Platelet Count Agar) was measured with an analytical balance. The PCA was diluted in $250 \mathrm{ml}$ distilled water in an Erlenmeyer flask. The solution was stirred while heating on a hotplate to eliminate clumping. The medium was covered with plastic wrap and sterilized in an autoclave at $121^{\circ} \mathrm{C}$ for 1 hour.

\subsection{Physiological Salt Solution}

$\mathrm{NaCl}(2.2 \mathrm{~g})$ was measured on an analytical balance. The $\mathrm{NaCl}$ was diluted in 250 $\mathrm{ml}$ of distilled water in a glass beaker and stirred with a spatula. Ten $\mathrm{ml}$ of the solution was measured using a graduated cylinder and put into test tubes. The test tubes were covered with cotton and plastic wrap and sterilized in an autoclave at $121^{\circ} \mathrm{C}$ for 1 hour.

\subsection{Petri dish sterilization}

Petri dishes were cleaned and dried completely. Each Petri dish was wrapped tightly with paper and put into a oven for approximately 3 hours to be sterilized.

\subsection{Media Dilution and Preparation}

Each sample was serially diluted to a 10-3 concentration All steps were done near a Bunsen burner and using different pipettes for each dilution to avoid crosscontamination or mixing. The Petri dish was mildly shaken to even the spread and then allowed to solidify for $10-15 \mathrm{~min}$. The Petri dish was wrapped in plastic wrap tightly and incubated for 1 day at $37^{\circ} \mathrm{C}$ in an incubator.

\subsection{Microorganism Cell Count}

Existing colonies were marked with a marker and counted with a bacterial colony counter. The total number of colonies was multiplied by $1,000 \mathrm{CFU} / \mathrm{ml}$.

\subsection{Data Analysis}

Results from the bacterial cell counts on agar media were analyzed using the Wilcoxon test to detect differences between groups before and after treatment and to determine the effectiveness of the treatment. A p-value $<0.05$ was considered significant.

\section{Results and Discussion}

This study aimed to determine the sterilization effectiveness of the Dekiler Box 
for medical instruments used in a student clinic at the Faculty of Dentistry of $\mathrm{Mu}$ hammadiyah University, Surakarta. The samples were dental instruments utilized in various treatment and examination procedures at the student clinic. The instruments used were given three treatments. That is, bacteria were observed on the instruments before they had been dipped in disinfectant solution (Fig 2). The instruments were examined after being used for dental treatment and examination and not sterilized, and the instruments were examined after dental treatment and sterilization using the Dekiler Box by measuring the decrease in the number of bacterial colonies observed by plate counts on agar media.

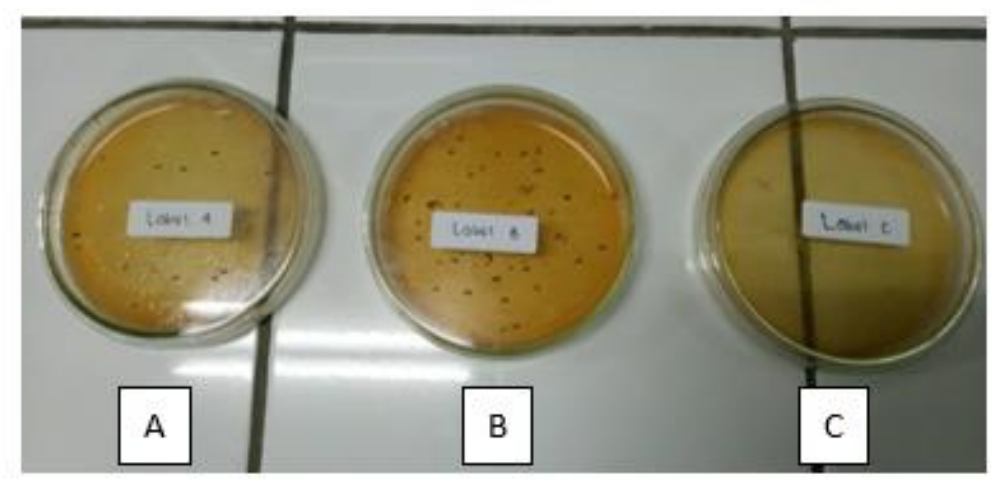

Fig 2. Bacterial colonies on dental instruments before being used for a dental examination (A), after use in an examination (B) and after sterilization with Dekiler Box (C).

The reduction in the number of bacterial colonies on the dental instruments. Column A shows the bacterial counts on the dental instruments before treatment and on those that had been disinfected. Column B shows the bacterial counts on instruments after treatment and observations. Column $\mathrm{C}$ shows the bacterial counts after the treatment and sterilization using the Dekiler Box.

No bacteria were detected on any of the semi-critical instruments sterilized with the Dekiler Box. The normality of the data before and after sterilization were tested using the Shapiro-Wilk test.

According to the Shapiro-Wilk normality test, the distribution of the bacterial count data was not normal ( $\mathrm{p}<0.05)$. The abnormal data distribution was normalized using data transformation and analyzed with the Wilcoxon test.

The Wilcoxon test results showed a significant difference between all treatment groups $(\mathrm{p}<0.05)$. This means that sterilization using the Dekiler Box was effective for reducing the bacterial counts on the dental instruments.

The instruments before use showed a minimum bacterium count of $0 \mathrm{CFU} / \mathrm{ml}$, and a maximum of $56.103 \mathrm{CFU} / \mathrm{ml}$. The bacterial counts on instruments after use in an examination and treatment were $0 \mathrm{CFU} / \mathrm{ml}$ at the minimum, and 264.103 $\mathrm{CFU} / \mathrm{ml}$ at the maximum. The bacterial count on instruments sterilized with the Dekiler Box was $0 \mathrm{CFU} / \mathrm{ml}$. 
A minimal bacterial count of $0 \mathrm{CFU} / \mathrm{ml}$ was found on mouth mirrors in group A, whereas a maximum bacterial count of $56.103 \mathrm{CFU} / \mathrm{ml}$ was found on the excavator and explorer. The minimal bacteria count was found on the mouth mirror in group B, and the maximum bacteria count of $264.103 \mathrm{CFU} / \mathrm{ml}$ was found on the explorer and excavator. The minimum bacteria count of $0 \mathrm{CFU} / \mathrm{ml}$ was found on all instruments in group $\mathrm{C}$. The Wilcoxon signed-rank test results showed a significant difference in bacterial counts between instruments before and after treatment $(\mathrm{p}<0.05)$, indicating the effectiveness of the Dekiler Box as multifunctional sterilization equipment to reduce bacterial counts on dental instruments.

In conclusion, the Dekiler Box is an innovative piece of sterilization equipment that was effective for reducing bacteria because it contains a pressure cooker which works on the same principle as an autoclave. These results are in accordance with several studies suggesting that the autoclave is the most used sterilization method because it gives the best result in eliminating all microorganisms [12].

\section{Conclusions}

We conclude that dental instruments sterilized using a Dekiler Box reduced bacterial counts on instruments. A significant difference was detected between the bacterial count on dental instruments before and after sterilization using the Dekiler Box.

\section{Acknowledgement}

We thank the Indonesian Directorate General of Higher Education as funders of our research.

\section{References}

1. Bare, BG. Brunner and Suddarth's textbook of medicalsurgical nursing 8 Ed Vol. 1.2. Jakarta: EGC; 2002.

2. Darmadi. Nosocomial infections: Problems and control. Jakarta: Publisher Salemba Medika. 2008;77-81.

3. Viana AC, Gonzalez BM, Buono VT, Bahia MG. Influence of sterilization on mechanical properties and fatigue resistance of nickel-titanium rotary endodontic instruments. Int Endodont J. 2006;39(9):709-15.

4. Ministry of Health. Standard Infection Prevention and Control Dental and Oral Health Care in Health Care Facilities. Jakarta: Ministry of Health. 2012.

5. Sunoto, RI. Precaution Transmission of Infectious Diseases In Dental Practice. Journal of PDGI. 55th ed.12. 2004.

6. Samaranayake, LP. Essential microbiology for dentistry. Churchill Livingstone 3rd ed. 2006; 337-339.

7. Mallick A, Khaliq SA, Muhammad N, Qureshi R. Practices of sterilization techniques at dental clinics of Karachi, Pakistan. Int J Pharm. 2014;4(1):108-2.

8. Kohn WG. Centers for Disease Control and Prevention: Guidelines for infection control in dental health care settings-2003. J Am Dent Assoc. 2004;135(1):33-47.

9. Tridianti A. The effectiveness of various methods of sterilization of contaminated molar band after band fitting process (test bacterial count). Jakarta: Program Specialist Orthodontics Faculty of Dentistry UI. 2012; 13-14. 
10. Herastuti, S, Wiworo, H, Siti Hidayati, et al. The Pan Press as a Tool Alternatives Autoclave Sterilization. Yogyakarta MOH polytechnic. 2015.

11. Brooks GF, Butel JS, Morse SA. Medical Microbiology. Jakarta: Salemba Medika. $2005 ; 124$.

12. Budiharto, Health research methodology (with examples of dental health science). Jakarta: EGC. 2008; 46.

13. Viana AC, Gonzalez BM, Buono VT, Bahia MG. Influence of sterilization on mechanical properties and fatigue resistance of nickel-titanium rotary endodontic instruments. Int Endodont J. 2006;39(9):709-15. 